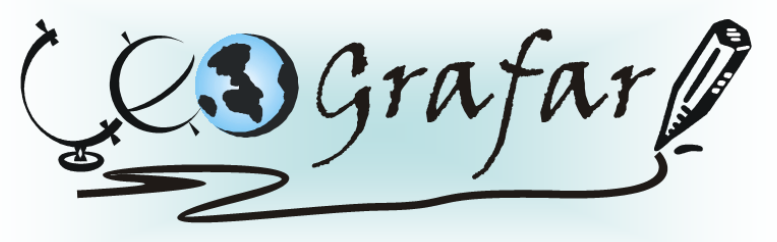

Revista Eletrônica do Programa de Pós-Graduação em Geografia - UFPR

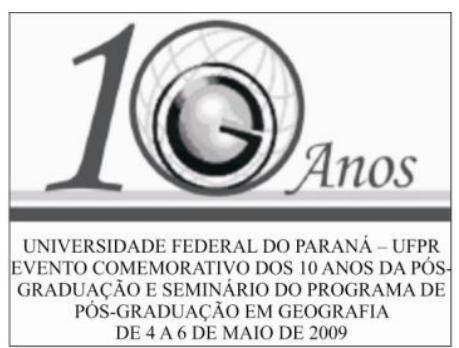

\title{
EVOLUÇÃO DA COBERTURA VEGETAL E USO DA TERRA NA BACIA HIDROGRÁFICA DO RIO SAGRADO - MORRETES - PR
}

\author{
CAROLINA MESQUITA ${ }^{1}$ \\ NALDY EMERSON CANALI ${ }^{2}$ \\ PAISAGEM E ANÁLISE AMBIENTAL
}

O Programa CAD (Contaminantes, Assoreamento e Dragagem da Baía de Paranaguá/PR) tem como objetivo investigar a dinâmica do assoreamento e da poluição do estuário de Paranaguá. Esse trabalho tem como finalidade detectar as mudanças da cobertura vegetal e do uso da terra na Bacia hidrográfica do Rio Sagrado, Morretes/PR. Ela é uma das bacias hidrográficas que mais contribuem com a produção de sedimentos no estuário de Paranaguá, decorrente de problemas relacionados à ocupação das áreas suscetíveis a processos erosivos e de movimentos de massa, sobretudo na Serra do Mar. Dentre os objetivos específicos, estão: georreferenciar e mosaicar as fotografias aéreas dos anos 1954, 1980, 1996 e 2005; levantar o histórico da ocupação dos municípios que estão inseridos na área de estudo e os impactos causados por essa ocupação; mapear a cobertura vegetal e uso da terra na área estudada; identificar os períodos de maior degradação da cobertura vegetal, os quais serão correlacionados às informações de assoreamento do estuário de Paranaguá; e a partir de SIG cruzar as informações e confeccionar o mapa das alterações ocorridas. A metodologia iniciará com o levantamento bibliográfico e dos materiais cartográficos disponíveis. A partir da elaboração dos mosaicos digitais será possível cruzar as informações por meio da ferramenta de SIG. Os softwares utilizados serão ArcGis 9.2, Global Mapper 8.0, Erdas Imagine 9.0 e Photoshop 7.0. A partir da conclusão dos mapas de uso da terra e de cobertura vegetal e de suas respectivas análises será possível detectar a matriz de mudança da cobertura vegetal e do uso da terra, bem como a quantidade absoluta e relativa de cada uma das classes de uso do solo em cada uma das datas. Com esta matriz e com os mapas pode-se

\footnotetext{
1 carolmes@hotmail.com

${ }^{2}$ Professor orientador
} 
calcular a taxa de degradação da vegetação entre as décadas de 1950 e 2010, verificando assim quais são as áreas que mais sofreram com a degradação nas últimas décadas, e assim, relacioná-las com o assoreamento do estuário de Paranaguá.

Palavras-chave: Uso da terra, Cobertura vegetal, SIG. 